\title{
Cervical lymphocele: A rare complication following salvage surgery for ocular adnexal apocrine adenocarcinoma. A case report and review of the literature
}

\author{
Lukas Hauera, Jiri Gencura , Petr Posta ${ }^{a}$, Zdenek Kasl' ${ }^{b}$, Stepan Rusnak ${ }^{b}$, Alena Skalovac, Miroslava Chalupova a, Jan Liskaa, \\ Vlasta Merglova ${ }^{a}$
}

Background. An ocular adnexal apocrine adenocarcinoma (OAAA) is an extremely rare, but potentially aggressive and life-threatening tumor with ill-defined management based only on recommendations from a limited number of reported cases. The development of cervical lymphocele following neck dissection is a very rare complication, but one with well established methods for prevention and treatment. Here we describe a previously unreported case of salvage surgery including neck dissection for OAAA in addition to an emergence of cervical lymphocele. A literature review of current knowledge on both pathological conditions is included.

Methods and Results. A 58-year-old man suffering from OAAA, previously treated with multiple eye-sparing excisions and adjuvant proton therapy, underwent salvage surgery for locoregional recurrence of the tumor. A partial orbitectomy with orbital exenteration, primary reconstruction and left-sided neck dissection was performed. The procedure was complicated by a cervical lymphocele resolved after the surgical therapy. The patient remained disease-free during the one-year follow-up.

Conclusion. OAAA is a locally aggressive tumor with potential to local or distant metastatic spread. Whole-body staging, regular clinico-radiological follow-up and stage-dependent therapy with surgery as the first-choice treatment is required. A cervical lymphocele as a complication of especially left-sided neck dissection is managed with a conservative or surgical therapy according to the level of lymph leakage, extent and localization of lesions, presence of local or systemic disorders and the period from primary surgery.

Key words: cervical lymphocele, thoracic duct injury, neck dissection, adnexal tumor, apocrine adenocarcinoma, orbit, salvage surgery

Received: July 23, 2020; Revised: October 20, 2020; Accepted: October 22, 2020; Available online: November, 26, 2020

https://doi.org/10.5507/bp.2020.051

(c) 2022 The Authors; https://creativecommons.org/licenses/by/4.0/

${ }^{a}$ Department of Dentistry, University Hospital and Faculty of Medicine in Pilsen, Charles University, Alej Svobody 80, 30460 Pilsen, Czech Republic

${ }^{b}$ Clinic of Ophthalmology, University Hospital and Faculty of Medicine in Pilsen, Charles University, Alej Svobody 80, 30460 Pilsen, Czech Republic

'Sikl's Department of Pathology, Faculty of Medicine in Pilsen, Charles University, Ed. Benese 13, 30599, Pilsen, Czech Republic

Corresponding author: Lukas Hauer, e-mail: hauerl@fnplzen.cz

\section{INTRODUCTION}

Apocrine adenocarcinomas arise from apocrine sweat glands occurring in the skin of the axilla or anogenital area, in the areola and nipple of the breast and in the auditory canal $1^{1,2}$. Ocular adnexal apocrine adenocarcinoma (OAAA) is an extremely rare tumor emerging from modified apocrine glands of the eyelids (glands of Moll), which are situated at the base of eyelash follicles. A quite unique origin of OAAA from sweat glands of the lacrimal caruncle or lacrimal sac was also described ${ }^{1,3,4}$. OAAA was first reported by Stout and Cooley in 1951 (ref. ${ }^{5}$ ) and only 30 cases have been reported since ${ }^{1,3,4,6}$. Because of its sporadic occurrence, little is known about the biological behaviour of this tumor. OAAA may follow a relatively indolent and protracted clinical course, but some tumors have the potential for rapid growth with deep soft tissue or bone invasion, recurrence, and regional lymph-node and even distant metastases ${ }^{2}$. OAAA usually manifests as an eyelid mass with a clinical appearance similar to a chalazion, leading to misdiagnoses and delay in treatment ${ }^{6}$. The paucity of data about OAAA has not yet enabled the establishment of a management standard for this malignant disease. Owing to potential of the metastases and deep invasion in OAAA, adequate clinical staging (ideally the whole-body) using imaging methods should be performed. The mainstay of treatment is surgical therapy, meaning en bloc excision or resection aiming at the achievement of histologically negative surgical margins on the entire surface of the specimen ${ }^{6}$. The appropriate size of the clinical surgical margins is unclear. Patients with orbital extension require exenteration, accompanied with orbitectomy in selected cases. For patients in whom lymph node involvement is suspected, therapeutic neck dissection is necessary. Radiotherapy is used to improve locoregional control in patients with an aggressive course of the disease. The role of chemotherapy is still unknown ${ }^{1}$. Primary determinants of patients' survival include an oc- 
currence of lymph node or distant metastases and local invasion into deep structures ${ }^{1}$.

Thoracic duct injuries associated with neck dissections (especially those including levels IV and VI) are infrequent but potentially lethal complications, with an estimated incidence of $1-6 \%$ (ref. $^{7}$ ). They may lead to a postoperative cervical lymphorrhea and development of chylous fistula, chylothorax or an exceptionally rare lymphocele $^{8}$. The cervical lymphocele (chyloma) is defined as a circumscribed lymph collection in a neocavity lacking an epithelial lining, which is predominantly left-sided ${ }^{9,10}$. These lesions may also develop following other neck surgical procedures, trauma or spontaneously, probably due to the congenital or acquired lymphatic vessel wall weakness and degeneration or obstruction at the terminal end of the duct. Spontaneous lymphoceles compared to postoperative ones usually have a simple endothelial lining revealed by histopathological analysis ${ }^{7}$. Current recommendations for the management of cervical lymphoceles following neck dissections were adapted from experiences with the therapy of these lesions in other localizations in the body.

Here we present a case report of salvage surgery including neck dissection for recurrent, metastatic OAAA with the further complication of a cervical lymphocele.
A review was carried out of all published cases dealing with both pathological conditions to improve knowledge of current management of these lesions.

\section{CASE REPORT}

A 57-year-old man consulted an ophthalmologist due to a one-month history of a swelling affecting the left lower eyelid. On clinical examination the eyelid margin and skin showed no visible pathology, but a painless indurated mass was palpable in the medial region. Visual acuity was unimpaired. During eye elevation (sursumduction), ocular motility was limited in the extreme position in the left eye with binocular diplopia in this position (vertical image disparity). A mild protrusion of the eyeball caused by the pathological process was found. Both eye anterior and posterior segment examinations were normal and other findings were in the physiological range. The medical history of the patient was irrelevant. The MRI revealed a hypervascular pathological mass $25 \times 20 \times 23 \mathrm{~mm}$ in extent predominantly infiltrating the medial half of the left orbital space with extension into the lower eyelid. The cranial part of the nasolacrimal duct was completely

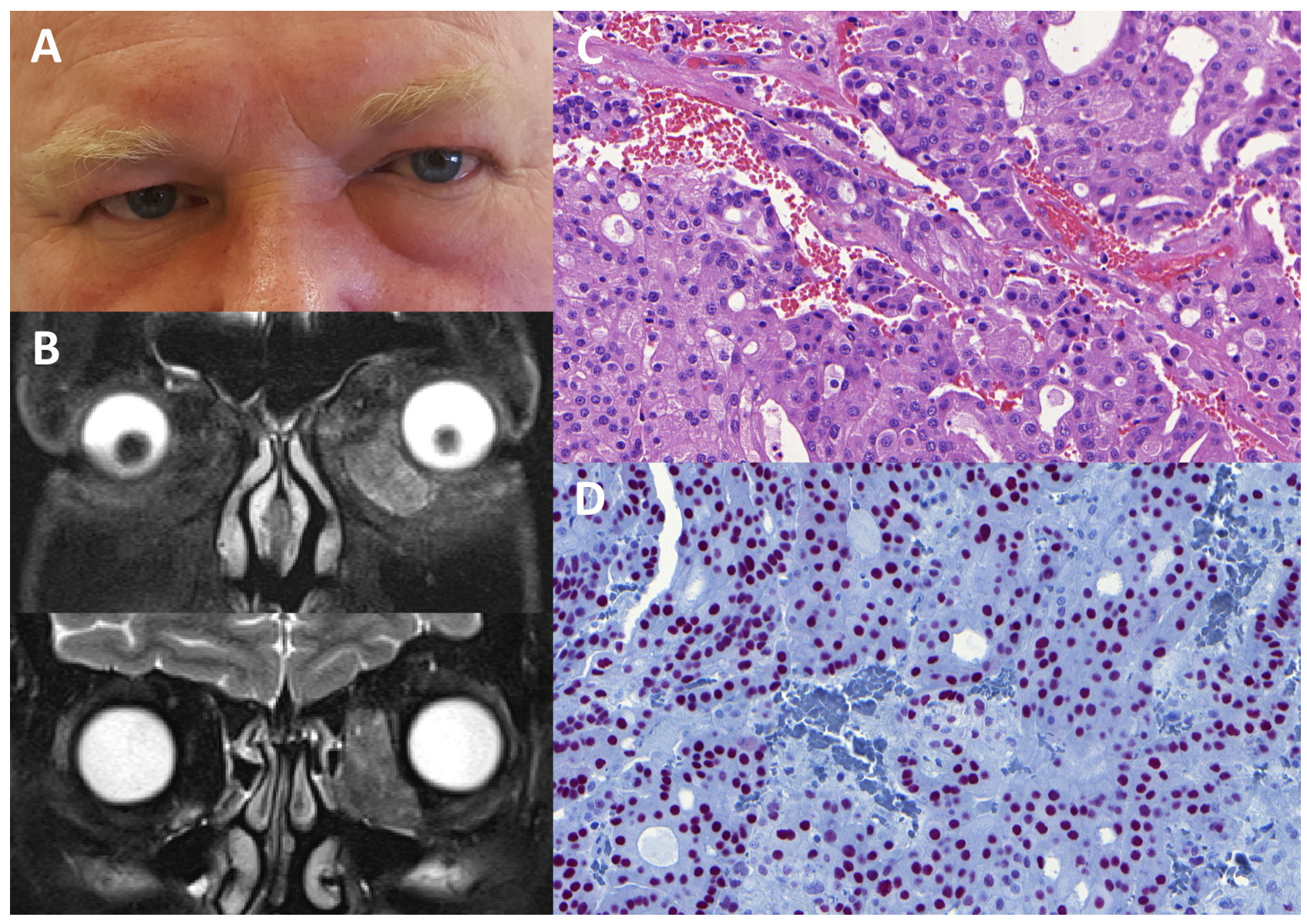

Fig. 1. (A) The clinical finding at the time of diagnosis, (B) T2-weighted coronal MRI scans (Image courtesy of Department of Imaging Methods, University Hospital and Faculty of Medicine in Pilsen, Charles University) and (C, D) histology and immunohistochemistry of ocular adnexal apocrine adenocarcinoma. (C) Hematoxylin-eosin stain: The tumor has a solid and tubular growth pattern and it is composed of polymorphic cells with abundant granular eosinophilic cytoplasm. (D) The cells reveal positive nuclear staining for androgen receptors (AR). 


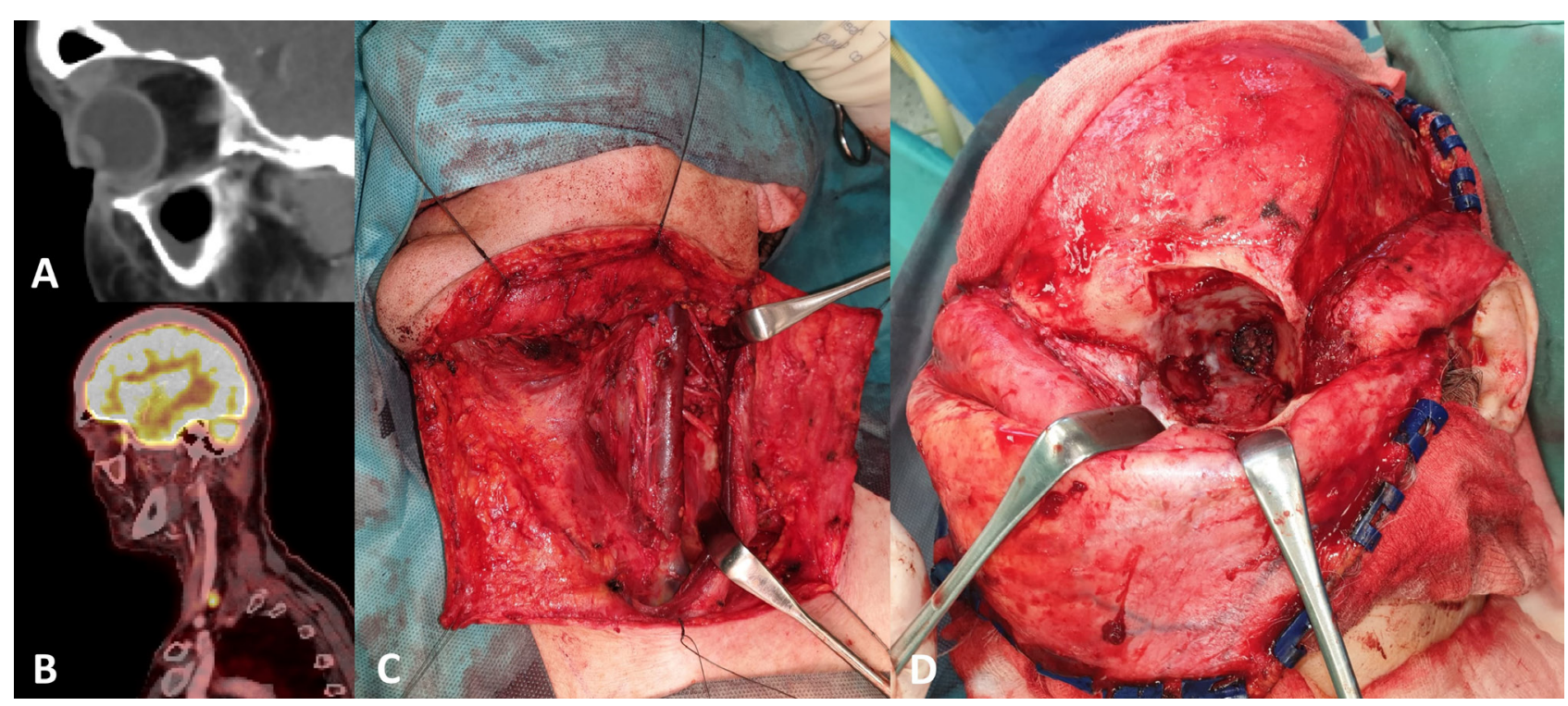

Fig. 2. (A) Sagittal CT and (B) 18F-FDG PET/CT scans showing the tumor recurrence and the lymph node suspicious for metastasis (Image courtesy of Department of Imaging Methods, University Hospital and Faculty of Medicine in Pilsen, Charles University). The state after the salvage surgery: (C) therapeutic neck dissection (ND L (I-V)) and (D) partial orbitectomy with the upper eyelid-sacrificing orbital exenteration. The temporalis muscle flap is prepared for orbital reconstruction.

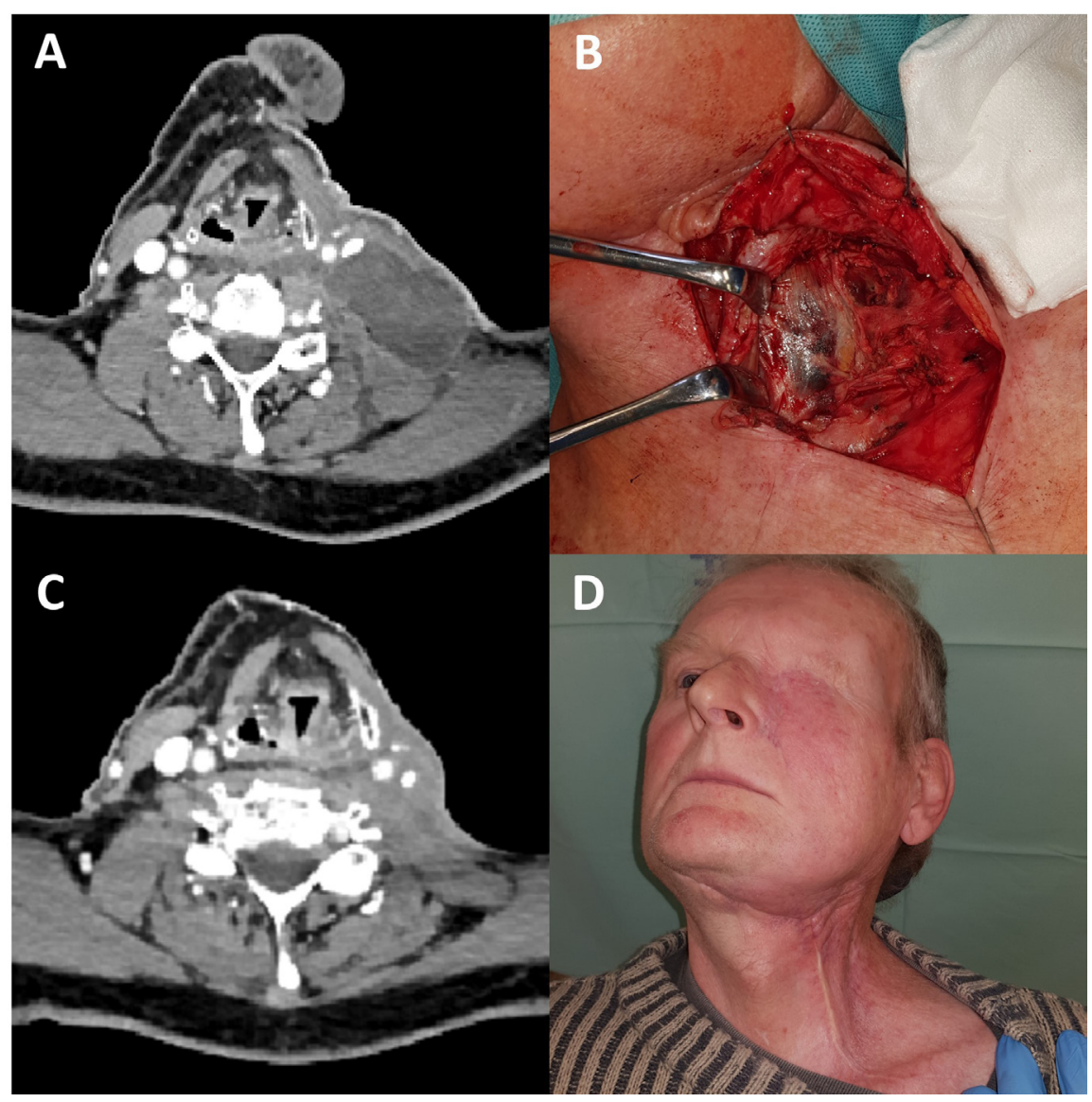

Fig. 3. (A) Axial CT scan showing the lymphocele in the left V neck level (Image courtesy of Department of Imaging Methods, University Hospital and Faculty of Medicine in Pilsen, Charles University) and (B) the intraoperative view of this lesion. (C) The axial CT scan (Image courtesy of Department of Imaging Methods, University Hospital and Faculty of Medicine in Pilsen, Charles University) and (D) clinical state after the lymphocele resolution. 


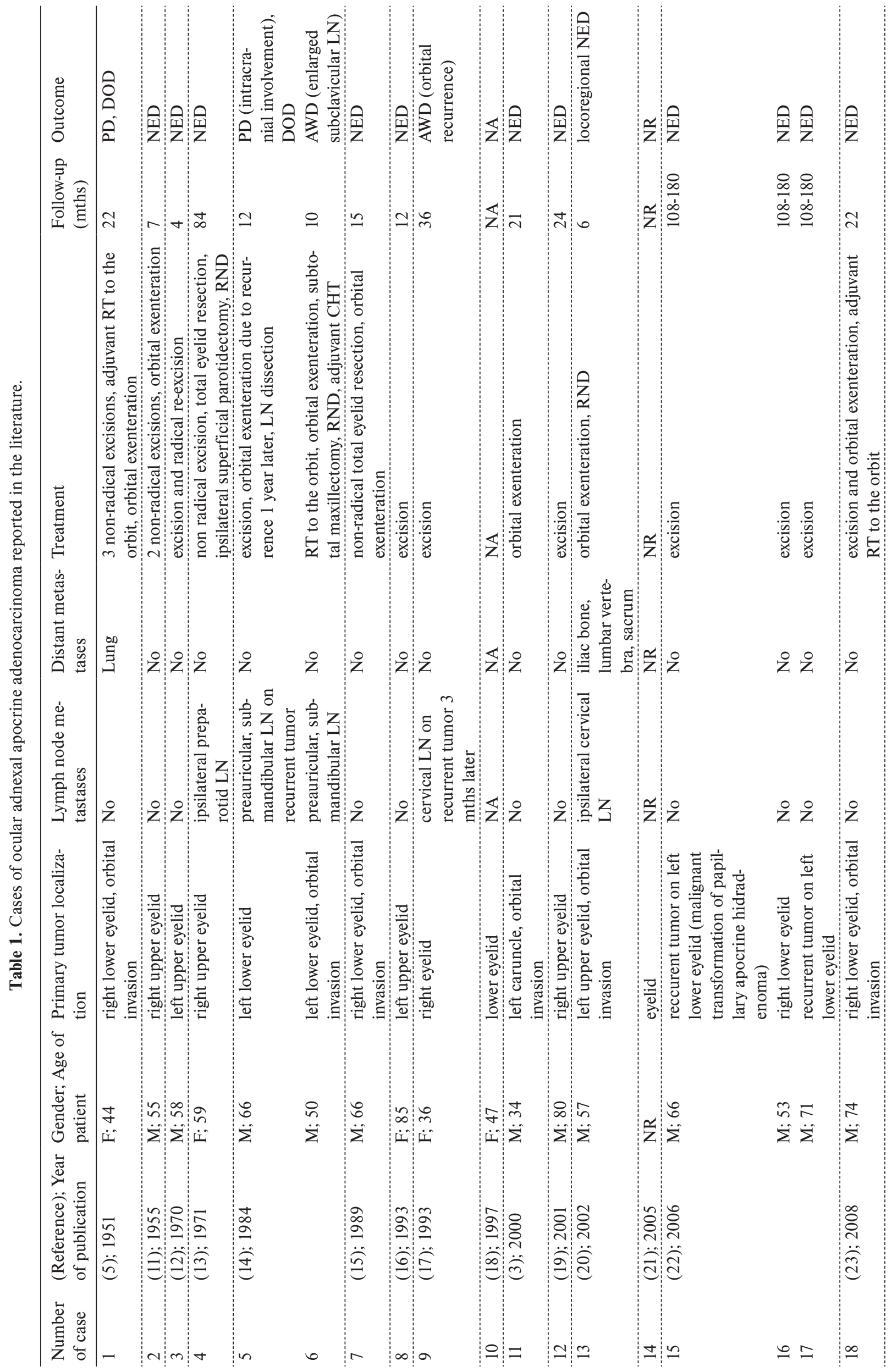




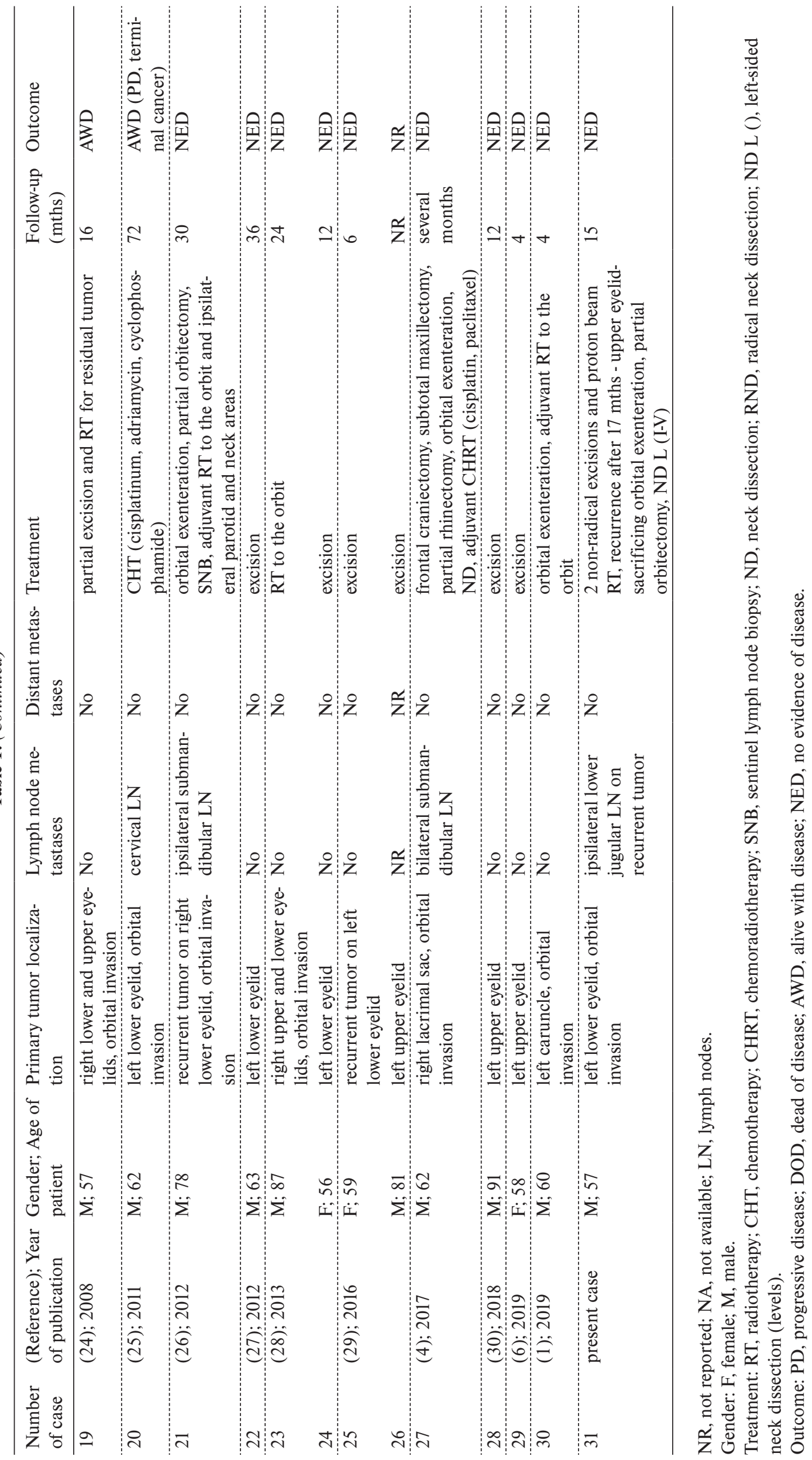


Table 2. Cases of cervical lymphoceles associated with neck dissections reported in the literature.

\begin{tabular}{|c|c|c|c|c|c|c|c|}
\hline $\begin{array}{l}\text { Number } \\
\text { of case }\end{array}$ & $\begin{array}{l}\text { (Reference); } \\
\text { Year of } \\
\text { publication }\end{array}$ & $\begin{array}{l}\text { Gender; } \\
\text { Age of } \\
\text { patient }\end{array}$ & Primary tumor & $\begin{array}{l}\text { Type of neck } \\
\text { dissection } \\
\text { (classification } \\
\text { corresponding with } \\
\text { published data) }\end{array}$ & $\begin{array}{l}\text { Side of } \\
\text { lymphocele }\end{array}$ & $\begin{array}{l}\text { Treatment of } \\
\text { lymphocele }\end{array}$ & $\begin{array}{l}\text { Outcome of } \\
\text { treatment }\end{array}$ \\
\hline 1 & $(33) ; 1989$ & F; 78 & $\begin{array}{l}\text { SCC of the skin } \\
\text { (mandibular angle) }\end{array}$ & RND & left & surgery & healed \\
\hline 2 & $(34) ; 2004$ & $\mathrm{~F} ; 24$ & $\begin{array}{l}\text { papillary thyroid } \\
\text { carcinoma }\end{array}$ & MRND & left & surgery & healed \\
\hline 3 & $(35) ; 2008$ & $\mathrm{M} ; 58$ & esophageal SCC & MRND & left & $\begin{array}{l}\text { OK-432 } \\
\text { sclerotherapy }\end{array}$ & healed \\
\hline 4 & & F; 59 & $\begin{array}{l}\text { papillary thyroid } \\
\text { carcinoma }\end{array}$ & MRND, CND & left & $\begin{array}{l}\text { OK-432 } \\
\text { sclerotherapy }\end{array}$ & healed \\
\hline 5 & & M; 65 & $\begin{array}{l}\text { hypopharyngeal } \\
\text { SCC }\end{array}$ & RND & right & $\begin{array}{l}\text { OK-432 } \\
\text { sclerotherapy }\end{array}$ & healed \\
\hline 6 & & M; 70 & SCC, unknown site & MRND & right & $\begin{array}{l}\text { OK-432 } \\
\text { sclerotherapy }\end{array}$ & healed \\
\hline 7 & $(7) ; 2011$ & NA & SCC, site NR & NR & $\begin{array}{l}\text { NR ( } 3 \text { separate } \\
\text { lymphoceles) }\end{array}$ & NR & NR \\
\hline 8 & & F; 37 & thyroid cancer & NR & bilateral & sclerotherapy & "good results" \\
\hline 9 & $(36) ; 2012$ & $\mathrm{~F} ; 37$ & $\begin{array}{l}\text { papillary thyroid } \\
\text { carcinoma }\end{array}$ & NR & left & surgery & healed \\
\hline 10 & $(37) ; 2012$ & $\mathrm{M} ; 65$ & $\begin{array}{l}\text { papillary thyroid } \\
\text { carcinoma }\end{array}$ & $\begin{array}{l}\text { MRND (IJV and } \\
\text { CN XI sparing) }\end{array}$ & left & surgery & healed \\
\hline 11 & & $\mathrm{M} ; 62$ & $\begin{array}{l}\text { papillary thyroid } \\
\text { carcinoma }\end{array}$ & $\begin{array}{l}\text { MRND (IJV, SCM } \\
\text { and CN XI sparing) }\end{array}$ & left & surgery & $\begin{array}{l}\text { chyle leak } \\
\text { persistence, } \\
\text { death of sepsis }\end{array}$ \\
\hline 12 & $(9) ; 2013$ & $\mathrm{~F} ; 31$ & $\begin{array}{l}\text { papillary thyroid } \\
\text { carcinoma }\end{array}$ & ND L $(I V, V I)$ & left & surgery & healed \\
\hline 13 & $(8) ; 2017$ & $\mathrm{~F} ; 64$ & oral SCC & RND & left & conservative & $\begin{array}{l}\text { no change, } \\
\text { death of } \\
\text { cancer }\end{array}$ \\
\hline 14 & present case & $\mathrm{M} ; 58$ & OAAA & ND L (I-V) & left & surgery & healed \\
\hline
\end{tabular}

NR, not reported.

Gender: F, female; M, male.

Primary tumor: SCC, squamous cell carcinoma; OAAA, ocular adnexal apocrine adenocarcinoma.

Type of neck dissection: RND, radical neck dissection; MRND, modified radical neck dissection; CND, central neck dissection; IJV, internal jugular vein; CN XI, spinal accessory nerve; SCM, sternocleidomastoid muscle; ND L (), left-sided neck dissection (levels).

involved and there was suspicion of the medial orbital wall invasion by the tumor. The eyeball was mildly displaced laterally. A biopsy was performed, resulting in a confirmatory diagnosis of OAAA (Fig. 1). Two non-radical eyesparing excisions of the tumor within two months were performed. The result of histopathological examination showed intermediate to high grade apocrine adenocarcinoma arising from a gland of Moll with lymphatic and perineural invasion. Assessment of proliferative activity using Ki-67/MIB-1 immunostaining revealed a low level of MIB-1 index, namely $10 \%$. Immunohistochemistry on formalin fixed paraffin embedded sections revealed positivity for cytokeratin CK-7 and AE1/3, epithelial membrane antigen (EMA) and androgen receptors (AR) (Fig. 1D). Immunostains were negative for CK-14 and CK-20. The detection of $\mathrm{p} 63$, SOX10, HER2/neu and S-100 proteins was also negative. The patient subsequently underwent adjuvant proton beam radiation therapy to the orbit and ipsilateral regional lymph nodes. Complete remission was attained but severe adverse effects of radiotherapy occurred. Radiation keratopathy with mycotic corneal ulcer and a secondary glaucoma led to total left eye blindness.

After 17 months of clinico-radiological follow-up, a locoregional recurrence of the tumor was discovered. A tumor mass (a size of 13x12x7 mm) under the left orbital roof in the extent of the frontal sinus base and a lymph node suspected of metastasis between IV and Vb neck levels were detected by the whole-body ${ }^{18} \mathrm{~F}-\mathrm{FDG}$ PET/ CT. The histopathological analysis of samples obtained from the core cut biopsy confirmed the tumor recurrence. Salvage surgery was performed. The procedure included an en bloc partial orbitectomy with the resection of the orbital roof corresponding with the floor of the frontal sinus, accompanied with upper eyelid-sacrificing orbital 
exenteration. This was performed from the anterior and coronal approach. The perioperative biopsy showed tumor-free superficial surgical margins. The orbital defect was reconstructed primarily with the temporalis muscle flap and cheek advancement flap. Therapeutic left-sided neck dissection of levels I-V was performed, sparing all non-lymphatic structures, with the dissection and ligation of the thoracic duct in order to achieve an oncological radicality (Fig. 2). The histopathological examination confirmed the recurrence of high-grade apocrine adenocarcinoma of identical histological structure with a bone, peri- and intraneural invasion. The MIB-1 index was 35\%. None of the fusion oncogenes were proven by molecular genetic testing using FusionPlex Solid Tumor, CTL and Sarcoma Kits (ArcherDX, Boulder, CO, USA). A positive surgical margin at one point was found ( $\mathrm{R} 1$ resection), but in this area, which was considered as the closest margin during the procedure, a further bone resection was added. Two lymph node metastases were detected in the specimen from the suspected region on PET/CT imaging (between IV and $\mathrm{Vb}$ neck levels). The postoperative course was uneventful except for the fact that the fluid from active drainage of the neck contained chyle. The chylous exudation ceased spontaneously on the third day after surgery and drains were removed. The wounds healed by the primary intention and the patient was without any further problems.

Three months later a cervical lymphocele $(6 \times 3 \times 7 \mathrm{~cm})$ localised in the $\mathrm{V}$ neck level on the left side was revealed on ${ }^{18} \mathrm{~F}$-FDG PET/CT. Only discreet swelling was clinically manifested in the relevant area of the neck. The lymphocele was first treated conservatively by repeated aspiration drainage and external compressions of the affected area for approximately one month. During the course of conservative management, the status was repeatedly monitored by a neck ultrasonography. This imaging showed a gradual mild progression of this lesion which became septated with minimal fluid content. Therefore, an extirpation of the lymphocele was performed. A lesion-feeding branch of the thoracic duct was identified and ligated. A small perforation detected in the main trunk was repaired by suture in combination with oxycellulose and the muscle flap from the dorsal edge of the sternocleidomastoid muscle. Histopathological examination revealed fibrofatty tissue with reparative changes, reactive fibroblastic proliferation and also necrosis, which supported the clinical diagnosis. The healing was uneventful (Fig. 3). During the one-year clinico-radiological follow-up using the wholebody ${ }^{18} \mathrm{~F}-\mathrm{FDG}$ PET/CT, the patient remained disease-free in terms of both tumor and lymphocele.

\section{DISCUSSION}

To date 27 cases of OAAA arising in eyelids, two cases originating from the lacrimal caruncle and one case from the lacrimal sac have been described in the literature (Table 1) (ref. ${ }^{1,3-6,11-30}$ ).

The male to female ratio of published cases was
2.8:1. The mean age of patients was 62.4 years (standard deviation 13.7 years, range 34-91 years, median $=59.5$ years). The lymph node metastases were detected in $32 \%$ $(9 / 28)$ and distant metastases to the lung and bone in $7 \%(2 / 28)$ of cases. These data were available only in 30 and 28 patients, respectively, including the presented case. According to published data, primary surgery for OAA was performed in $90 \%$ (26/29) of cases. During the course of the disease, orbital exenteration was required in $41 \%(12 / 29)$ of patients and $21 \%(6 / 29)$ of patients had to undergo some type of neck dissection. The radiotherapy, especially as an adjuvant treatment, was indicated in $31 \%$ $(9 / 29)$ of patients. These data were available only in 29 patients, including the presented case, which is the first reported case of salvage surgery including neck dissection due to multiple lymph node metastases. The surgery of OAAA performed in the previously irradiated field is reported only in two cases in the literature. Stout and Cooley described the salvage orbital exenteration without neck dissection following three non-radical tumor excisions and the adjuvant radiotherapy to the orbit ${ }^{5}$. The progressive course of this disease with the evidence of lung metastases resulted in patient's death. Ni et al. described the patient suffering from OAAA primarily treated with radiotherapy to the orbit ${ }^{14}$. The radiation exposure of 4000 roentgen in 29 days was used followed by the orbital exenteration and subtotal maxillectomy with the addition of neck dissection and the adjuvant chemotherapy in the further course of the disease ${ }^{14}$. But these surgical procedures cannot be called salvage surgery. This patient with the evidence of the enlarged subclavicular lymph node was lost to follow-up. Out of all published cases, 75\% (21/28) of patients were disease free during the follow-up. But in most cases this follow-up involved an insufficient period for malignant disease: only in five patients did it exceed five years.

The thoracic or right lymphatic ducts have potential for numerous anatomical anomalies of their drainage to a cervical venous system in the lower neck. Multiple thoracic duct terminations in one or more veins are described in $10-45 \%$ of cases $^{9,31}$. In addition, the walls of these lymphatic structures are extremely thin, fragile and difficult to identify in fatty tissue. The anatomy of this region may be further complicated by the presence of aberrant thoracic duct branch terminating on the right side. A real right-sided duct occurs with an incidence rate of about $4 \%$ (ref. $^{32}$ ). For these reasons, peroperative injuries to the thoracic duct may be easily overlooked. In the presented case, a lymph leak occurred probably because of these facts despite the meticulous identification, dissection and ligation of the duct to achieve an oncological radicality in IV and $\mathrm{Vb}$ neck levels.

For prevention of thoracic duct injury, a thorough knowledge of the normal and aberrant anatomy of the lymphatic system and painstaking dissection without undue traction of these structures is necessary. At the end of the operation, the surgical field should be systematically examined for chyle leakage, especially if thoracic duct breach is suspected. This requires lowering the patient's 
head and performing the Valsalva maneuver ${ }^{8,31}$. If any breach with lymph leak is detected, a functional repair is enabled by suturing the perforation. It may be reinforced with local hemostatic agents (e.g. gelatin, oxycellulose, fibrin glue) alone, or in combination with adjacent fascia, local muscle flap or autologous fat graft $^{8}$. If the suture is not feasible, a ligation of the duct may be another option. An active drain has to be positioned away from the site of lymphatic structures closure to avoid the direct aspiration of the lymph from this area ${ }^{9}$. The postoperative surveillance should include systematic observation of the drainage liquid quality and examination of the surgical area for any signs suggestive of lymph leakage (red and sensitive skin with induration caused by intense inflammatory reaction to lymph) (ref. ${ }^{9}$ ). An accumulation of lymph in the wound may cause fluid and electrolyte shifts, protein loss, as well as compromising local healing ${ }^{8}$. The postoperative lymphorrhea may sometimes resolve spontaneously, leads to chylous fistula, chylothorax or on rare occasions to later development of lymphocele. So far, only 16 cases of lymphoceles following neck dissections have been published (Table 2) (ref..$^{7-9,33-37}$ ).

Our case was successfully treated surgically with no signs of recurrence during the follow-up. So far, only six cases of cervical lymphoceles following neck dissections managed surgically with the success rate of $83 \%(5 / 6)$ have been reported in the literature ${ }^{9,33,34,36,37}$. The lymphocele should be suspected when a patient develops a cervical mass in the neck dissection area. A fluctuation with overlying edema and erythema may be found out on physical examination ${ }^{31}$. Imaging methods such as ultrasound, CT and MRI are not contributive to diagnosis but may be helpful for determination the exact localization and extension of the lesion, its character (cystic or solid) and also relations to the surrounding structures ${ }^{8}$. Establishing the diagnosis of postoperative cervical lymphocele is based upon identifying the cyst fluid is chylous in origin. Therefore, an aspiration of the liquid is required for evaluation of its appearance and performing biochemical analysis. The pathognomonic hallmark is a creamy or milky fluid with increased cholesterol and triglyceride levels which are higher than in the blood $^{8,9}$.

Conservative management performed approximately for up to one month should be the first-line approach in the treatment of postoperative cervical lymphocele in cases of low-level lymph leakage ( $<100 \mathrm{~mL} /$ day) (ref., ${ }^{9,38}$ ). Diet modification has been shown to reduce the production of chyle. Enteric regimes include low-fat diet with medium-chain triglycerides which are directly absorbed by the portal venous system, bypassing the lymphatics ${ }^{9,38}$. Total parenteral nutrition eliminates any gastrointestinal absorption of fat and may be considered as an alternative. Somatostatin analogs (octreotide) are also used as a concomitant therapy for reduction of intestinal fat absorption and production of lymph ${ }^{32,38}$. Dietary modification was not applied in the presented case in order not to impair the nutritional status of the oncological patient. Other conservative measures comprise an ensuring elevation of the head, repeated aspiration drainage and applying external compression of the affected area ${ }^{9,38}$. In patients refractory to conservative management, more invasive procedures like the transcutaneously instillation of sclerosing agents such as OK-432, doxycycline, bleomycine, talc or povidone-iodine can be considered ${ }^{8,9,31}$.

Surgery is indicated in cases of lymph leakage exceeding $600 \mathrm{~mL} /$ day or after failure of the conservative approach ${ }^{9}$. Revision surgery should be performed before local (a cutaneous involvement with wound healing disorders) or systemic complications arise (due to loss of electrolytes, liquids and proteins). Late indication for surgery is associated with elevated risk of injury to adjacent neuro-vascular structures because the preparation within the area of newly-formed granulation and fibrous tissue is challenging ${ }^{9,31}$. A preoperative administration of milk or cream may facilitate localization of the leak ${ }^{9,31}$. Surgical therapy includes extirpation of the lesion and above-mentioned procedures aimed at closing the thoracic duct or recreating the lymphovenous connection ${ }^{38}$. In patients who do not respond to this treatment, in cases of leakage exceeding $1000 \mathrm{~mL} /$ day and/or in lesions associated with chylothorax, ligature of the thoracic duct performed through an open thoracotomy or using less traumatic thoracoscopic approaches is required ${ }^{9}$. Other treatment options for lymphatic-chylous leaks such as a therapeutic lymphography, thoracic duct embolization or microsurgical derivative multiple lymphatic-venous anastomoses may be considered ${ }^{38}$.

\section{CONCLUSION}

OAAA is a locally aggressive tumor with potential to local or distant metastatic spread. Whole-body staging, regular clinico-radiological follow-up and stage-dependent therapy with the surgery as the first-choice treatment is required. A cervical lymphocele as a complication of especially left-sided neck dissection is managed with a conservative or surgical therapy according to the level of lymph leakage, extent and localization of lesions, presence of local or systemic disorders and the period from primary surgery.

Author contributions: LH: manuscript writing, literature search, data analysis and interpretation; JG, PP, ZK, SR, MC, JL: literature search, data analysis and interpretation; AS: histological assessment, review of the manuscript, final approval; VM: review of the manuscript, final approval. All authors read and approved the final manuscript as submitted.

Conflict of interest statement: None declared.

\section{REFERENCES}

1. Shashni AK, Sen S, Meel R, Sharma MC, Nag TC. Primary apocrine adenocarcinoma of caruncle in an elderly male. Can J Ophthalmol 2019;54(3):e123-5.

2. Zhang L, Ge S, Fan X. A brief review of different types of sweat-gland carcinomas in the eyelid and orbit. Onco Targets Ther 2013;6:331-40. 
3. Duke TG, Fahy GT, Brown LJ. Malignant apocrine sweat gland carcinoma of the caruncle. Orbit 2000;19(1):7-11.

4. Hoang A, Khine KT, Zaldivar R. Apocrine adenocarcinoma of lacrimal sac presenting as chronic dacryocystitis. J Ophthalmic Clin Res 2017;4(1):027.

5. Stout AP, Cooley SG. Carcinoma of sweat glands. Cancer 1951;4(3):521-36.

6. Rosales Santillan M, Tschen JA, Soparkar CN. Apocrine adenocarcinoma of the eyelid: case report and literature review on management. Dermatol Online J 2019;25(5). pii: 13030/qt2p62h61q.

7. Hamilton BE, Nesbit GM, Gross N, Andersen P, Sauer D, Harnsberger HR. Characteristic imaging findings in lymphoceles of the head and neck. AJR Am J Roentgenol 2011;197(6):1431-5.

8. Kimura M, Ohto H, Shibata A, Yamada H, Nishiwaki S, Umemura M. Cervical chyloma after neck dissection: a case report. Nagoya J Med Sci 2017;79(1):91-5.

9. Laccourreye O, Espinoza S, Mukundian S, Bonfils P. Prevention and cure of lymphorrhea and lymphocele after cervical lymph-node surgery. Eur Ann Otorhinolaryngol Head Neck Dis 2013;130(4):229-32.

10. Stárek I, Salzman R, Pokorná Z, Skanderová D. Cyst of the right lymphatic duct. Eur Ann Otorhinolaryngol Head Neck Dis 2020;137(2):123-5.

11. Whorton CM, Patterson JB. Carcinoma of Moll's glands with extramammary Paget's disease of the eyelid. Cancer 1955;8(5):1009-15.

12. Aurora AL, Luxenberg MN. Case report of adenocarcinoma of glands of Moll. Am J Ophthalmol 1970;70(6):984-90.

13. Futrell JW, Krueger GR, Chretien PB, Ketcham AS. Multiple primary sweat gland carcinomas. Cancer 1971;28(3):686-91.

14. Ni C, Wagoner M, Kieval S, Albert DM. Tumours of the Moll's glands. Br J Ophthalmol 1984;68(7):502-6.

15. Thomson SJ, Tanner NS. Carcinoma of the apocrine glands at the base of eyelashes; a case report and discussion of histological diagnostic criteria. Br J Plast Surg 1989;42(5):598-602.

16. Seregard S. Apocrine adenocarcinoma arising in Moll gland cystadenoma. Ophthalmology 1993;100(11):1716-9.

17. Paties C, Taccagni GL, Papotti M, Valente G, Zangrandi A, Aloi F. Apocrine carcinoma of the skin. A clinicopathologic, immunocytochemical, and ultrastructural study. Cancer 1993;71(2):375-81.

18. Simionescu C, Damian C. Adenocarcinoma of Moll's glands. Oftalmologia 1997;41(4):333-4.

19. Paridaens D, Mooy CM. Apocrine sweat gland carcinoma. Eye (Lond) 2001;15(Pt 2):253-4.

20. Shintaku M, Tsuta K, Yoshida H, Tsubura A, Nakashima Y, Noda K. Apocrine adenocarcinoma of the eyelid with aggressive biological behavior: report of a case. Pathol Int 2002;52(2):169-73.

21. Pornpanich K, Chindasub P. Eyelid tumors in Siriraj Hospital from 2000-2004. J Med Assoc Thai 2005;88 Suppl 9:S11-4.
22. Barker-Griffith AE, Streeten BW, Charles NC. Moll gland neoplasms of the eyelid: a clinical and pathological spectrum in 5 cases. Arch Ophthalmol 2006;124(11):1645-9.

23. Kanazawa S, Kubo T, Tañag M, Yamaguchi Y, Hoshida Y, Yano K Hosokawa K. Apocrine adenocarcinoma originating from the Moll's gland of the eyelid: Report of a case. Eur J Plast Surg 2008;31(6):3336.

24. Akcay EK, Simsek S, Cagil N, Belenli O, Gumus M. Apocrine adenocarcinoma of the right eyelid and apocrine adenoma of the left maxillary sinus. Can J Ophthalmol 2008:43(5):609-10.

25. Kumar S, Zafar SF, Raufi AM, Heath El. Apocrine carcinoma of the face in a 62-year-old Asian man. Clin Pract 2011;1(3):e50.

26. Valenzuela AA, Cupp DG, Heathcote JG. Primary apocrine adenocarcinoma of the eyelid. Orbit 2012;31(5):316-8.

27. Hunold AC, Herwig MC, Holz FG, Fischer HP, Loeffler KU. Pigmented tumour of the eyelid with unexpected findings. Case Rep Pathol 2012;2012:471368.

28. Figueira EC, Danks J, Watanabe A, Khong JJ, Ong L, Selva D. Apocrine adenocarcinoma of the eyelid: case series and review. Ophthalmic Plast Reconstr Surg 2013;29(6):417-23.

29. Aldrees SS, Zoroquiain P, Alghamdi SA, Logan P, Kavalec C, Burnier M. Apocrine adenocarcinoma of the eyelid. Int J Ophthalmol 2016;9(7):1086-8

30. Pagano Boza C, Vigo R, Premoli JE, Croxatto J, Gonzalez Barlatay J. A case report of a primary apocrine adenocarcinoma of the eyelid with literature review. Orbit 2018;37(5):389-92.

31. Seelig MH, Klingler PJ, Oldenburg WA. Treatment of a postoperative cervical chylous lymphocele by percutaneous sclerosing with povidone-iodine. J Vasc Surg 1998;27(6):1148-51.

32. Touska P, Constantinides VA, Palazzo FF. A rare complication: lymphocele following a re-operative right thyroid lobectomy for multinodular goitre. BMJ Case Rep 2012;2012. pii: bcr0220125747.

33. Chantarasak DN, Green MF. Delayed lymphocoele following neck dissection. Br J Plast Surg 1989:42(3):339-40.

34. Nouwen J, Hans S, Halimi P, Laccourreye O. Lymphocele after neck dissection. Ann Otol Rhinol Laryngol 2004;113(1):39-42.

35. Roh JL, Park Cl. OK-432 sclerotherapy of cervical chylous lymphocele after neck dissection. Laryngoscope 2008;118(6):999-1002.

36. Al-Suqri B, Dutton J. latrogenic chyloma in the neck: lymphoscintigraphic findings. Clin Nucl Med 2012;37(11):1126-8.

37. Thiagarajan S, Shenoy AM, Veerabadriah P, Chavan P, Halkud R. Massive Chylorrhea following Total Thyroidectomy and Neck Dissection. Int J Head Neck Surg 2012;3(1):45-8.

38. Campisi CC, Boccardo F, Piazza C, Campisi C. Evolution of chylous fistula management after neck dissection. Curr Opin Otolaryngol Head Neck Surg 2013;21(2):150-6. 